\title{
Pengembangan Formula Gel Ekstrak Teh Hijau (Camellia sinensis L.) sebagai Penyubur Rambut
}

\section{Development of Green Tea Extract Gel (Camellia sinensis L.) as Hair Fertilizer}

\author{
Novena Yety Lindawati, Lusia Murtisiwi, C.E. Dhurhania*) \\ ${ }^{*}$ Akademi Farmasi Nasional Surakarta \\ *) Jl. Yos Sudarso No. 338, Surakarta, Jawa Tengah, Indonesia
}

\section{Intisari}

Kerontokan rambut merupakan masalah yang dapat mengganggu penampilan. Ekstrak teh hijau dengan kadar $5 \%$ terbukti menstimulasi pertumbuhan rambut (Sumakdjaja, dkk., 2008). Zat aktif dalam teh hijau (Camellia sinensis L) yang berkhasiat sebagai penyubur rambut adalah senyawa katekin dan turunannya. Senyawa flavonoid teh hijau terdiri dari epikatekin, (EC), epikatekin galat (ECG), dan epigalokatekin galat (EGCG). Selain itu juga terdapat asam galat, galokatekin galat (GCG), galokatekin (GC), katekin galat (CG) katekin (C), vitamin B dan vitamin C (Agus, 2007) yang mampu memperkuat akar rambut, mencegah kerontokan rambut, menghambat radikal bebas, menetralkan racun, dan melindungi kulit kepala dari infeksi. Formula sediaan kosmetik dan makanan berbahan aktif the hijau telah menyita perhatian masyarakat. Penyubur rambut berbahan aktif ekstrak teh hijau berbentuk gel belum dijumpai di kalangan masyarakat. Berdasarkan fenomena tersebut, penelitian ini bertujuan mengembangkan formula gel penyubur rambut berbahan aktif ekstrak teh hijau.

Penelitian ini dilakukan dengan membuat empat formula, yaitu formula I (carbopol 1\%, TEA 0,3\%, gliserin $1 \%$ ), formula II (CMC Na 3\%, gliserin $1 \%$,), formula III (PEG $40072 \%$, PEG 4000 8\%, gliserin 1\%) dan formula IV (carbopol 0,75\%, TEA 2\%, PEG $40012 \%$ gliserin $1 \%$. Masing-masing formula mengandung ekstrak teh hijau dengan kadar $5 \%$, pengawet nipagin $0,1 \%$, dan natrium metabisulfit $0,1 \%$, sediaan dibuat 100 gram. Keempat gel yang diperoleh kemudian diuji kualitas sediaannya meliputi uji organoleptis, uji homogenitas, uji $\mathrm{pH}$, uji daya sebar, uji daya lekat, uji daya proteksi, uji iritasi primer, uji aseptabilitas, serta uji aktivitas penyubur rambut.

Dari penelitian diketahui bahwa formula gel yang paling optimal adalah formula I yang terdiri dari carbopol $1 \%$, TEA 0,3 \%, dan gliserin $1 \%$. Formula I menunjukkan konsistensi gel yang baik, mempunyai aktivitas penyubur rambut paling tinggi, tidak mengiritasi kulit, serta mempunyai sifat aseptabilitas yang baik.

\section{Kata kunci: formula gel, Camellia sinensis L, ekstrak teh hijau, kerontokan rambut, penyubur rambut}

\begin{abstract}
Hair loss is can be a fashionable matter. Green tea extract which the concentration is about $5 \%$ can stimulate hair growing (Sumakdjaja, et.al., 2008). The compound in green tea extract are catecine and their derivate. They are epicatecine (EC), epicatecine galat (ECG), and epigalocatecine (EGCG). In green tea axtract there are also contains galat acid, galocatecine galat (GCG), galocatecine (GC), catecine galat (CG), catecine (C), vitamin $B$ and vitamin $C$ (Agus, 2007) which can make hair root stronger, prefent hair loss, to inhibit free radical, neutralize poisson, and protect head skin from infection. People more interest to use cosmetics and foods with green tea
\end{abstract}


extract. There is no hair growth stimulating gel with green tea extract in the market. This is the reason of this research, is to develope hair growth stimulating gel formula.

There are four formula in this research. They are formula I (carbopol $1 \%$, TEAO 3\%, and glycerine $1 \%$ ), formula II (CMC Na 3\% and glycerine $1 \%$ ), formula III (PEG $40072 \%$, PEG $40008 \%$, and glycerine 1\%) and formula IV (carbopol 0,75\%, TEA 2\%, PEG 400 12\%, and glycerine 1\%). The concentration of green tea axtract in each formula are $5 \%$. In each formula contains $0,1 \%$ nipagin as a preservative, and $0,1 \%$ sodium metabisulfit. The quality of each gel formula tested by organoleptic test, homogenity test, $\mathrm{pH}$ test, spread test, thickening test, protection test, primary iritation test, aceptability test, and hair growth stimulating activity test.

Keywords: gel formula, Camellia sinensis L, green tea extract, hair loss, hair growth stimulating agent

\section{Pendahuluan}

Penyakit atau kelainan pada rambut merupakan suatu hal yang mencemaskan. Kecemasan ini wajar karena rambut memang mempunyai banyak manfaat, baik dari segi kesehatan maupun keindahan. Bagi wanita rambut adalah mahkota kecantikan, sedangkan bagi kaum pria rambut adalah lambang kejantanan dan keperkasaan. Kelainan pada kulit rambut dan kulit kepala dapat memicu terjadinya kerontokan rambut. Apabila kerontokan rambut terjadi secara berlebih, maka dapat menimbulkan kebotakan. Tak heran jika perawatan rambut secara eksklusif telah banyak diminati oleh masyarakat saat ini.

Teh hijau (Camellia sinensis L.) dapat berkhasiat sebagai penyubur dan penghitam rambut (Setiawan, 1999). Teh hijau merupakan salah satu jenis teh yang diproduksi dari daun teh yang diuapkan dan dikeringkan tanpa proses fermentasi. Teh hijau mengandung polifenol utama dalam daun teh dengan jumlah yang lebih banyak dibanding teh hitam. Zat aktif dalam teh hijau yang berkhasiat sebagai penyubur rambut adalah senyawa flavonoid, khususnya katekin dan turunannya.

Senyawa flavonoid teh hijau terdiri dari epikatekin (EC), epikatekin galat (ECG), epigalokatekin (EGC), dan epigalokatekin galat (EGCG). Selain itu terdapat juga asam galat, galokatekin galat (GCG), galokatekin (GC), katekin galat (CG), katekin (C). Teh hijau juga mengandung asam amino, vitamin B, dan vitamin C (Agus, 2007), yang mampu memberikan asupan nutrisi untuk memperkuat akar rambut, mencegah kerontokkan rambut, menghambat radikal bebas, menetralkan racun, dan melindungi kulit kepala dari infeksi. Kandungan kimia tersebut juga mampu menimbulkan efek relaksasi jika berada di bawah sinar matahari, maupun pada kondisi rambut stres yang umumnya dialami setelah melakukan pewarnaan rambut secara bergantian (Anonim, 2007).

Formula sediaan kosmetik dan makanan berbahan aktif teh hijau telah banyak menyita perhatian masyarakat. Respon masyarakat terhadap khasiat teh hijau cukup positif. Hal ini didukung oleh semakin bertambahnya produk-produk kosmetik dan makanan yang diformulasi dengan teh hijau. Bahkan pembalut wanita ada yang dibuat dengan aroma teh hijau. Penyubur rambut berbahan aktif ekstrak teh hijau yang berbentuk gel belum dijumpai di kalangan masyarakat. Berdasarkan fenomena tersebut, melalui penelitian ini hendak dikembangkan formula gel penyubur rambut berbahan aktif ekstrak teh hijau.

Gel adalah bentuk sediaan setengah padat yang transparan, tembus cahaya atau buram, tidak berlemak, merupakan sistem dispersi yang terdiri dari partikel-partikel organik makromolekul, biasanya untuk pemakaian luar. Produk-produk baru berbentuk gel semakin bertambah antara lain: gel masker wajah, gel penata rambut, gel antiseptik, gel obat urut ataupun obat gosok karena respon masyarakat yang cukup positif terhadap bentuk sediaan gel yang lembut di tangan dan berwarna transparan.

Basis gel yang ideal bersifat inert dan tidak bereaksi dengan komponen lain. Basis 
yang baik adalah basis yang tidak terikat terlalu kuat dengan obat, karena obat harus mampu lepas dari basis sebelum menembus kulit. Ada dua tahapan kerja obat topikal agar mampu memberikan efek, antara lain obat harus dapat lepas dari basis dan menuju ke permukaan kulit, selanjutnya berpenetrasi melalui membran kulit untuk mencapai tempat aksinya. Faktor-faktor yang mempengaruhi kedua tahapan tersebut adalah kondisi kulit; sifat fisikokimia obat, seperti: kelarutan obat dalam basis, koefisien partisi, koefisien difusi; dan sifat fisikokimia basis gel, seperti: ukuran partikel, viskositas basis, dan $\mathrm{pH}$ basis.

Berdasarkan penelitian yang telah dilakukan oleh Sukmadjaja dkk., (2008) tentang uji efektivitas ekstrak teh hijau terhadap pertumbuhan rambut yang diaplikasikan pada mencit BALB/c jantan dengan kadar 2,5\% dan 5\%, diketahui bahwa ekstrak teh hijau dengan kadar 5\% menunjukkan kelebatan rambut yang paling besar dan dapat menstimulasi pertumbuhan rambut.

Berdasarkan latar belakang yang telah dipaparkan, hasil penelitian awal tersebut masih memerlukan pengembangan ke dalam bentuk sediaan farmasi dengan formula gel yang optimal sebelum diaplikasikan oleh masyarakat luas. Oleh karena itu, dilakukan penelitian tentang pengembangan formula gel ekstrak teh hijau (Camellia sinensis L.) sebagai penyubur rambut. Untuk melihat potensi gel penyubur rambut yang dibuat maka dilakukan uji aktivitasnya terhadap mencit BALB/c jantan. Selain itu dilakukan uji stabilitas, uji aseptabilitas, dan uji iritasi sediaan sehingga didapatkan formula gel yang optimal.

\section{Metode Penelitian}

Bahan yang digunakan dalam penelitian ini adalah teh hijau (Camellia sinensis L), yang diperoleh di Pasar Harjodaksino, kecamatan Serengan, Surakarta yang diserbuk dengan mesin penyerbuk sampai didapatkan serbuk dengan derajat halus yang sesuai untuk maserasi.

\section{A. Cara Kerja}

\section{Penyiapan simplisia daun teh hijau}

Simplisia kering daun teh hijau diserbuk menggunakan mesin penyerbuk dengan derajat kehalusan yang sesuai untuk maserasi.

\section{Pembuatan ekstrak teh hijau}

Dimasukkan 10 bagian serbuk daun teh hijau dalam bejana. Tuangi dengan 75 bagian etanol $96 \%$, tutup dan biarkan selama 5 hari terlindung dari cahaya sambil berulang kali diaduk. Setelah 5 hari, diserkai, ampas diperas. Tambahi ampas dengan etanol 96\% secukupnya diaduk dan diserkai, sehingga diperoleh seluruh sari sebanyak 100 bagian. Tutup sari, biarkan ditempat sejuk, terlindung cahaya, selama 2 hari. Pisahkan endapannya. Sari langsung dipakai sebagai tingtur. Pekatkan sari dengan penyulingan (destilasi biasa). Dilanjutkan dengan penguapan di atas penangas air sampai terbentuk ekstrak kental.

\section{Desain Formula}

Rancangan formula sediaan gel penyubur rambut dapat dilihat pada Tabel I.

Tabel I. Rancangan formula gel penyubur rambut ekstrak teh hijau

\begin{tabular}{|c|c|c|c|c|}
\hline BAHAN & F I & F II & F III & F IV \\
\hline $\begin{array}{l}\text { Ekstrak teh } \\
\text { hijau }\end{array}$ & $5 \%$ & $5 \%$ & $5 \%$ & $5 \%$ \\
\hline Carbopol & $1 \%$ & - & - & $0,75 \%$ \\
\hline TEA & $0,3 \%$ & - & - & $2 \%$ \\
\hline $\mathrm{CMC} \mathrm{Na}$ & - & $3 \%$ & - & - \\
\hline PEG 400 & - & - & $72 \%$ & $12 \%$ \\
\hline PEG 4000 & - & - & $8 \%$ & - \\
\hline Gliserin & $1 \%$ & $1 \%$ & $1 \%$ & $1 \%$ \\
\hline $\begin{array}{l}\text { Natrium } \\
\text { metabisulfit }\end{array}$ & $0,1 \%$ & $0,1 \%$ & $0,1 \%$ & $0,1 \%$ \\
\hline Nipagin & $0,1 \%$ & $0,1 \%$ & $0,1 \%$ & $0,1 \%$ \\
\hline Akuades & \multicolumn{4}{|c|}{ ad $100 \mathrm{~g}$} \\
\hline
\end{tabular}

4. Pembuatan gel

a) Pembuatan larutan nipagin. Serbuk nipagin dilarutkan dengan 5 bagian etanol 96\%, aduk sampai larut.

b) Pembuatan sediaan gel dengan basis carbopol._Carbopol dikembangkan dalam air panas, kemudian diaduk sampai homogen dan tidak ada gumpalan. Tambahkan ekstrak daun teh hijau yang sebelumnya telah dicampur dengan sebagian air menggunakan magnetic stirrer $700 \mathrm{rpm}$ selama 10 menit, aduk sampai dingin. Masukkan bahan-bahan lain, selain 
TEA, ke dalam campuran tersebut. Kemudian tambahkan air sampai hampir mencapai bobot yang dikehendaki, tambahkan TEA sedikit demi sedikit sambil diaduk sampai terbentuk gel jernih. Tambahkan sisa air hingga mencapai bobot yang dikehendaki.

c) Pembuatan sediaan gel dengan basis CMC Na. CMC-Na dikembangkan dalam air, kemudian diaduk sampai sampai homogen dan tidak ada gumpalan. Tambahkan ekstrak daun teh hijau yang sebelumnya telah dicampur dengan sebagian air menggunakan magnetic stirrer $700 \mathrm{rpm}$ selama 10 menit, aduk sampai dingin. Masukkan bahan-bahan lain, ke dalam campuran tersebut. Kemudian tambahkan air sampai hampir mencapai bobot yang dikehendaki.

d) Pembuatan gel dengan basis PEG. Lebur PEG 400 dan PEG 4000 di atas waterbath. Masukkan leburan tersebut ke dalam mortir panas dan kering, aduk sampai homogen dan dingin. Tambahkan ekstrak daun teh hijau yang sebelumnya telah dicampur dengan sebagian air menggunakan magnetic stirrer $700 \mathrm{rpm}$ selama 10 menit, aduk sampai dingin. Masukkan bahan-bahan lain, ke dalam campuran tersebut. Kemudian tambahkan air sampai hampir mencapai bobot yang dikehendaki.

e) Pembuatan sediaan gel dengan kombinasi basis carbopol dan PEG. Carbopol dikembangkan dalam air panas, kemudian diaduk sampai homogen dan tidak ada gumpalan. Tambahkan ekstrak daun teh hijau yang sebelumnya telah dicampur dengan PEG menggunakan magnetic stirrer $700 \mathrm{rpm}$ selama 10 menit, aduk sampai dingin. Masukkan bahanbahan lain, selain TEA, ke dalam campuran tersebut. Kemudian tambahkan air sampai hampir mencapai bobot yang dikehendaki, tambahkan TEA sedikit demi sedikit sambil diaduk sampai terbentuk gel jernih. Tambahkan sisa air hingga mencapai bobot yang dikehendaki.

\section{Uji stabilitas fisik}

a) Uji Organoleptis, meliputi bentuk, warna, dan bau sediaan. Amati dan catat apabila terjadi perubahan bentuk, warna, dan bau dari sediaan gel.

b) Uji homogenitas. Oleskan gel pada kaca preparat secara merata, bila masih terasa kasar maka gel dikatakan tidak homogen.

c) Uji pH. Teteskan sediaan pada kertas $\mathrm{pH}$ kemudian bandingkan dengan standar $\mathrm{pH}$ berdasarkan warna yang terjadi.

d) Uji daya sebar. Timbang 0,5 g gel, letakkan di tengah kaca bundar. Letakkan kaca penutup yang telah diketahui beratnya di atas massa gel dan biarkan selama 1 menit. Ukur diameter gel yang menyebar (dengan mengambil rata-rata diameter dari 4 sisi). Tambahkan $50 \mathrm{~g}$ beban tambahan, diamkan selama 1 menit kemudian ukur diameter penyebaran gel. Lakukan percobaan sebanyak 2 kali lagi, dengan beban tambahan 50 g pada tiap kali penambahan beban, diamkan 1 menit, dan ukur diameter penyebaran gel

e) Uji daya lekat. Letakkan 0,5 g gel di atas kaca preparat yang telah ditentukan luasnya. Letakkan kaca preparat lain di atas gel tersebut. Tekan dengan beban $0,5 \mathrm{~kg}$ selama 5 menit. Pasang kedua kaca preparat yang telah saling berlekatan tersebut pada alat uji, kemudian lepaskan beban seberat $80 \mathrm{~g}$ dan catat waktu yang diperlukan hingga kedua kaca preparat terlepas

f) Uji daya proteksi. Ambil sepotong keras saring $(10 \times 10 \mathrm{~cm})$. Basahi dengan larutan phenolphthalein (pp) sebagai indikator. Setelah itu kertas dikeringkan. Olesi kertas tersebut dengan 0,5 g gel pada satu sisi permukaan seperti lazimnya orang menggunakan gel (1). Buat area 2,5 x $2,5 \mathrm{~cm}$ dengan pembatas parafin padat yang dilelehkan pada kertas saring yang lain (2). Tempelkan kertas (2) di atas (1). Tetesi area dengan $\mathrm{NaOH} 0,02$ N. Amati timbulnya noda kemerahan pada bagian kertas 
yang dibasahi dengan larutan PP. Catat waktu yang diperlukan mulai saat penetesan $\mathrm{NaOH}$ hingga munculnya warna merah

\section{Uji Aseptabilitas}

Uji aseptabilitas pemakaian sediaan dilakukan terhadap 20 responden laki-laki berusia diatas 20 tahun. Parameter uji yang diamati antara lain: pengolesan, kelembutan, efek dingin, pengeringan, dan daya lengket. Ketentuan penelitian untuk tiap parameter uji dilambangkan dengan tanda,+++ , dan +++ dengan makna sebagaimana dipaparkan dalam tabel II.

Tabel II. Parameter penilaian uji aseptibilitas

\begin{tabular}{|c|c|c|c|}
\hline$\underset{r}{\text { Paramete }}$ & + & ++ & +++ \\
\hline$\underset{\mathrm{n}}{\text { Pengolesa }}$ & $\begin{array}{l}\text { Tidak } \\
\text { mudah } \\
\text { merata }\end{array}$ & $\begin{array}{l}\text { Mudah } \\
\text { merata }\end{array}$ & $\begin{array}{l}\text { Sangat } \\
\text { mudah } \\
\text { merata }\end{array}$ \\
\hline $\begin{array}{c}\text { Kelembuta } \\
\mathrm{n} \\
\end{array}$ & $\begin{array}{l}\text { Sedikit } \\
\text { lembut }\end{array}$ & Lembut & $\begin{array}{l}\text { Sangat } \\
\text { lembut }\end{array}$ \\
\hline $\begin{array}{c}\text { Efek } \\
\text { dingin }\end{array}$ & $\begin{array}{l}\text { Sedikit } \\
\text { dingin }\end{array}$ & Dingin & $\begin{array}{l}\text { Sangat } \\
\text { dingin }\end{array}$ \\
\hline $\begin{array}{c}\text { Pengeringa } \\
\text { n gel }\end{array}$ & $\begin{array}{c}\text { Lambat } \\
\text { mengering }\end{array}$ & $\begin{array}{l}\text { Agak cepat } \\
\text { mengering }\end{array}$ & $\begin{array}{c}\text { Cepat } \\
\text { mengering }\end{array}$ \\
\hline $\begin{array}{c}\text { Daya } \\
\text { lengket }\end{array}$ & $\begin{array}{c}\text { Lengket } \\
\text { sekali }\end{array}$ & Lengket & $\begin{array}{c}\text { Tidak } \\
\text { lengket }\end{array}$ \\
\hline
\end{tabular}

\section{Uji iritasi primer}

Uji iritasi primer yang dilakukan meggunakan metode Draize yang telah dimodifikasi. Sejumlah 0,5 gram gel dioleskan pada hewan uji, kemudian ditutup dengan perban. Tempelan dibiarkan di kulit selama 4 jam, kemudian diambil dan diamati terjadinya eritema dan edema pada interval waktu 1 jam; 24 jam; 48 jam; 72 jam; 1 minggu. Terjadinya eritrema dan edema diberi skor sesuai dengan tabel evaluasi reaksi iritasi kulit (tabel III).

Tabel III. Evaluasi reaksi iritasi kulit (Lu,

\begin{tabular}{|c|c|c|}
\hline & $\frac{1995)}{\text { Jenis iritasi }}$ & Skor \\
\hline \multirow[t]{6}{*}{ Eritema } & Tanpa eritema & 0 \\
\hline & Eritema hampir tidak tampak & 1 \\
\hline & Eritema berbatas jelas & 2 \\
\hline & Eritema moderat sampai berat & 3 \\
\hline & $\begin{array}{l}\text { Eritema berat (merah bit) } \\
\text { sampai sedikit membentuk }\end{array}$ & 4 \\
\hline & kerak & \\
\hline \multirow[t]{5}{*}{ Edema } & Tanpa edema & 0 \\
\hline & Edema hampir tidak tampak & 1 \\
\hline & Edema tepi berbatas jelas & 2 \\
\hline & $\begin{array}{l}\text { Edema moderat ( tepi naik } \pm 1 \\
\mathrm{~mm} \text { ) }\end{array}$ & 3 \\
\hline & $\begin{array}{l}\text { Edema berat ( tepi naik lebih } \\
\text { dari } 1 \mathrm{~mm} \text { dan meluas keluar } \\
\text { daerah pejanan) }\end{array}$ & 4 \\
\hline
\end{tabular}

Untuk penentuan indeks iritasi primer menurut metode Draize maka skor eritrema dan edema keseluruhan ditambahkan dari jam ke-24 sampai jam ke-72 kemudian dibagi dengan jumlah hewan uji digunakan. Kriteria iritasi dicocokkan dengan tabel IV.

Tabel IV. Kriteria Iritasi (Lu, 1995)

\begin{tabular}{cc}
\hline _Indeks iritasi & $\begin{array}{c}\text { Kriteria iritasi } \\
\text { senyawa kimia }\end{array}$ \\
\hline$<2$ & Kurang merangsang \\
\hline $2-5$ & Iritan moderat \\
\hline$>6$ & Iritan berat \\
\hline
\end{tabular}

\section{Uji aktivitas penyubur rambut}

Siapkan hewan uji, cukur rambut hewan uji dengan ukuran $2 \times 2 \mathrm{~cm}^{2}$, olesi bagian yang telah tercukur dengan gel yang telah dibuat. Pengolesan dilakukan sekali sehari selama 1 bulan. Amati pertumbuhan rambut hewan uji pada akhir percobaan. Lakukan hal yang sama untuk masing-masing gel yang telah dibuat. Replikasi untuk masing formula gel sebanyak tiga kali (Sumakdjaja, 2008).

\section{B. Analisis Data}

Data yang terkumpul dari hasil uji stabilitas fisik, uji aseptabilitas, uji iritasi primer, dan uji aktivitas penyubur rambut dibandingkan secara deskriptif dengan hasil uji yang dipersyaratkan ataupun dengan kriteria penilaian dari masing-masing parameter. Dengan demikian dapat diketahui sediaan gel ekstrak teh hijau dengan stabilitas fisik terbaik, aseptabilitas terbaik, tidak mengiritasi, dan dengan aktivitas penyubur rambut terbaik.

\section{Hasil dan Pembahasan}

\section{A Pembuatan Ekstrak Kental Teh Hijau (Camellia sinensis $\mathrm{L}$ )}

Pada penelitian ini simplisia yang digunakan adalah teh hijau (Camellia sinensis L), yang diperoleh di Pasar Harjodaksino, Surakarta. Simplisia diserbuk dengan mesin penyerbuk sampai didapatkan serbuk dengan derajat halus yang sesuai untuk maserasi. Sepuluh (10) bagian serbuk teh hijau yang diperoleh dimasukkan dalam bejana, dituangi dengan 75 bagian etanol $96 \%$, ditutup dan biarkan selama 5 hari terlindung dari cahaya sambil berulang kali diaduk. Maserat yang 
diperoleh dipekatkan dengan penyulingan, sari yang didapatkan diuapkan di atas waterbath sampai terbentuk ekstrak kental. Metode ekstraksi yang dipilih adalah metode maserasi karena senyawa flavonoid dalam teh hijau larut dalam pelarut organik seperti etanol. Maserasi merupakan metode ekstraksi yang sederhana namun tetap memungkinkan didapatkannya rendemen yang relatif banyak. Ekstrak kental teh hijau yang diperoleh berupa ekstrak berwarna hijau kehitaman, dengan bau khas teh hijau.

Pembuatan gel ekstrak teh hijau dilakukan dengan empat formula dengan kombinasi basis gel yang berbeda, seperti yang tercantum dalam tabel II. Konsentrasi ekstrak teh hijau dalam gel masing-masing 5\% didasarkan pada penelitian Sumakdjaja, dkk (2008). Keempat formula gel dibuat masingmasing dengan replikasi tiga kali. Gel yang didapatkan kemudian diuji, meliputi uji stabilitas fisik (uji organoleptis, uji homogenitas, uji $\mathrm{pH}$, uji daya sebar, uji daya lekat, dan uji daya proteksi), uji aseptabilitas, serta uji aktivitas penyubur rambut.

\section{B. Uji stabilitas fisik gel ekstrak teh hijau (Camellia sinensis $\mathrm{L}$ ).}

Gel formula I, II, dan IV menunjukkan konsistensi gel yang cukup baik dan homogen, berwarna hijau tua, beraroma khas teh hijau. Gel teh hijau formula II menunjukkan konsistensi gel yang kurang baik karena berbentuk cair, warna dan aromanya sama dengan ketiga formula yang lain. Hal ini menunjukkan bahwa formula III yang merupakan kombinasi PEG 400 dan PEG 4000 72:8 kurang baik sebagai basis gel teh hijau. Optimasi formula dengan basis PEG dilakukan dengan mengubah perbandingan komponennya menjadi PEG 400:PEG 4000 65:15, namun dengan kombinasi ini pun menghasilkan konsistensi sediaan yang cair, sehingga basis PEG dikatakan kurang sesuai sebagai basis gel teh hijau.

\section{2) $\underline{\mathrm{Uji}} \mathrm{pH}$}

Uji $\mathrm{pH}$ sediaan gel bertujuan untuk melihat kesesuaian $\mathrm{pH}$ gel dengan $\mathrm{pH}$ kulit. Hasil uji $\mathrm{pH}$ terhadap keempat formula gel dapat dilihat pada tabel VII.

Sediaan topikal yang baik mamiliki $\mathrm{pH}$ yang sesuai dengan rentang $\mathrm{pH}$ kulit normal. Hasil uji $\mathrm{pH}$ menunjukkan semua $\mathrm{pH}$ gel keempat formula adalah 5 , hal ini sesuai dengan $\mathrm{pH}$ kulit yaitu antara 3,5-5.

Uji stabilitas fisik gel ekstrak teh hijau (Camellia sinensis $\mathrm{L}$ ) yang dilakukan meliputi uj organoleptis, uji homogenitas, uji $\mathrm{pH}$, uji daya $\mathrm{a}_{\mathrm{ka}}$

Tabel VI. Uji pH sebar, uji dava lekat, dan uji dava proteksi. si Hasil uji stabilitas fisik gel dapat dilihat pada tabel VI, VII, VIII, IX, dan X.

\section{1) Uji Organoleptis dan homogenitas}

Hasil uji organoleptis dan homogenitas gel dapat dilihat pada tabel VI.

Tabel V. Uji organoleptis dan uji homogenitas

\begin{tabular}{ccccc} 
Sifat & \multicolumn{4}{c}{ Formula } \\
\cline { 2 - 5 } fisik & I & II & III & IV \\
\hline Bentuk & $\begin{array}{c}\text { Semi } \\
\text { padat } \\
\text { (gel) }\end{array}$ & $\begin{array}{c}\text { Semi } \\
\text { padat } \\
\text { (gel) }\end{array}$ & Cair & $\begin{array}{c}\text { Semi } \\
\text { padat } \\
\text { (gel) }\end{array}$ \\
\hline Warna & $\begin{array}{c}\text { Hijau } \\
\text { tua }\end{array}$ & $\begin{array}{c}\text { Hijau } \\
\text { tua }\end{array}$ & $\begin{array}{c}\text { Hijau } \\
\text { tua }\end{array}$ & $\begin{array}{c}\text { Hijau } \\
\text { tua }\end{array}$ \\
\hline Bau & $\begin{array}{c}\text { Teh } \\
\text { hijau }\end{array}$ & $\begin{array}{c}\text { Teh } \\
\text { hijau }\end{array}$ & $\begin{array}{c}\text { Teh } \\
\text { hijau }\end{array}$ & $\begin{array}{c}\text { Teh } \\
\text { hijau }\end{array}$ \\
\hline $\begin{array}{c}\text { Homoge } \\
\text { nitas }\end{array}$ & $\begin{array}{c}\text { Homo } \\
\text { gen }\end{array}$ & $\begin{array}{c}\text { Homo } \\
\text { gen }\end{array}$ & $\begin{array}{c}\text { Homo } \\
\text { gen }\end{array}$ & $\begin{array}{c}\text { Homo } \\
\text { gen }\end{array}$ \\
\hline
\end{tabular}

\section{3) Uji daya sebar}

Uji daya sebar dilakukan dengan tujuan untuk melihat kemampuan gel menyebar pada kulit saat digunakan. Syarat gel yang baik adalah mempunyai kemampuan daya sebar yang cukup tinggi sehingga dapat meratakan efek farmakol ogi yang timbul. Kemampuan penyebaran ini akan mempengaruhi luas area kulit yang diolesi dan berkaitan dengan luas area kulit yang menyerap zat aktif gel. Hasil uji daya sebar gel teh hijau formula 9, II, III, dan IV dapat dilihat pada tabel VII, VIII IX, dan X. 
Tabel VII. Hasil uji daya sebar formula I

\begin{tabular}{|c|c|c|c|c|c|c|c|c|c|c|c|c|}
\hline \multirow{3}{*}{$\begin{array}{c}\text { Beban } \\
\text { (g) }\end{array}$} & \multicolumn{12}{|c|}{ Diameter penyebaran $(\mathrm{cm})$} \\
\hline & \multicolumn{4}{|c|}{ Formula I Replikasi 1} & \multicolumn{4}{|c|}{ Formula I Replikasi 2} & \multicolumn{4}{|c|}{ Formula I Replikasi 3} \\
\hline & $\mathbf{R} 1$ & $\mathbf{R} 2$ & R3 & $\begin{array}{c}\text { Rata- } \\
\text { rata }\end{array}$ & $\mathbf{R} 1$ & $\mathbf{R} 2$ & R3 & $\begin{array}{c}\text { Rata- } \\
\text { rata }\end{array}$ & R1 & $\mathbf{R} 2$ & R3 & $\begin{array}{l}\text { Rata- } \\
\text { rata }\end{array}$ \\
\hline Kaca & 4,2 & 4,2 & 4,1 & 4,2 & 4,4 & 4,4 & 4,4 & 4,4 & 4,3 & 4,5 & 4,7 & 4,5 \\
\hline 50 & 5,1 & 4,7 & 4,5 & 4,8 & 5,1 & 5,1 & 5,0 & 5,1 & 4,6 & 4,8 & 5,0 & 4,8 \\
\hline 100 & 5,2 & 4,9 & 5,0 & 5,0 & 5,4 & 5,3 & 5,3 & 5,3 & 4,8 & 5,1 & 5,3 & 5,1 \\
\hline 150 & 5,5 & 5,1 & 5,2 & 5,3 & 5,8 & 5,7 & 5,6 & 5,7 & 5,3 & 5,5 & 5,5 & 5,4 \\
\hline
\end{tabular}

Tabel VIII. Hasil uji daya sebar formula II

\begin{tabular}{|c|c|c|c|c|c|c|c|c|c|c|c|c|}
\hline \multirow{3}{*}{$\begin{array}{c}\text { Beban } \\
\text { (g) }\end{array}$} & \multicolumn{12}{|c|}{ Diameter penyebaran $(\mathrm{cm})$} \\
\hline & \multicolumn{4}{|c|}{ Formula I Replikasi 1} & \multicolumn{4}{|c|}{ Formula I Replikasi 2} & \multicolumn{4}{|c|}{ Formula I Replikasi 3} \\
\hline & $\mathbf{R} 1$ & $\mathbf{R} 2$ & R3 & $\begin{array}{c}\text { Rata- } \\
\text { rata }\end{array}$ & $\mathbf{R} 1$ & $\mathbf{R} 2$ & R3 & $\begin{array}{c}\text { Rata- } \\
\text { rata }\end{array}$ & $\mathbf{R} 1$ & $\mathbf{R} 2$ & R3 & $\begin{array}{c}\text { Rata- } \\
\text { rata }\end{array}$ \\
\hline Kaca & 6,0 & 7,0 & 6,7 & 6,6 & 5,3 & 5,3 & 5,6 & 5,4 & 5,5 & 5,7 & 5,5 & 5,6 \\
\hline 50 & 6,8 & 7,9 & 7,4 & 7,4 & 6,5 & 6,2 & 6,4 & 6,4 & 6,1 & 6,0 & 5,9 & 6,0 \\
\hline 100 & 7,2 & 8,5 & 7,7 & 7,8 & 6,6 & 6,6 & 6,9 & 6,7 & 6,6 & 6,1 & 6,4 & 6,4 \\
\hline 150 & 7,5 & 8,6 & 8,0 & 8,0 & 6,8 & 6,9 & 7,4 & 7,0 & 7,0 & 6,5 & 6,6 & 6,7 \\
\hline
\end{tabular}

Tabel IX. Hasil uji daya sebar formula III

\begin{tabular}{|c|c|c|c|c|c|c|c|c|c|c|c|c|}
\hline \multirow{3}{*}{$\begin{array}{c}\text { Beban } \\
\text { (g) }\end{array}$} & \multicolumn{12}{|c|}{ Diameter penyebaran $(\mathrm{cm})$} \\
\hline & \multicolumn{4}{|c|}{ Formula I Replikasi 1} & \multicolumn{4}{|c|}{ Formula I Replikasi 2} & \multicolumn{4}{|c|}{ Formula I Replikasi 3} \\
\hline & $\mathbf{R} 1$ & $\mathbf{R} 2$ & R3 & $\begin{array}{c}\text { Rata- } \\
\text { rata }\end{array}$ & $\mathbf{R} 1$ & $\mathbf{R} 2$ & R3 & $\begin{array}{c}\text { Rata- } \\
\text { rata }\end{array}$ & R1 & $\mathbf{R 2}$ & R3 & $\begin{array}{c}\text { Rata- } \\
\text { rata }\end{array}$ \\
\hline Kaca & 7,5 & 6,9 & 7,1 & 7,2 & 7,8 & 7,1 & 7,3 & 7,4 & 7,5 & 7,2 & 7,6 & 7,4 \\
\hline 50 & 8,2 & 7,8 & 8,0 & 8,0 & 8,6 & 7,6 & 8,2 & 8,1 & 8,3 & 7,9 & 8,4 & 8,2 \\
\hline 100 & 8,6 & 8,3 & 8,4 & 8,4 & 9,0 & 7,9 & 8,7 & 8,5 & 8,7 & 8,4 & 8,9 & 8,7 \\
\hline 150 & 9,2 & 8,9 & 9,0 & 9,0 & 9,4 & 8,4 & 9,1 & 8,9 & 9,1 & 8,7 & 9,4 & 9,1 \\
\hline
\end{tabular}

Tabel X. Hasil uji daya sebar formula IV

\begin{tabular}{cccccccccccccc}
\hline $\begin{array}{c}\text { Beban } \\
\text { (g) }\end{array}$ & \multicolumn{10}{c}{ Formula I Replikasi 1 } & \multicolumn{10}{c}{ Formula I Replikasi 2 } & \multicolumn{3}{c}{ Formula I Replikasi 3 } \\
\cline { 2 - 14 } & R1 & $\mathbf{R 2}$ & $\mathbf{R 3}$ & $\begin{array}{c}\text { Rata- } \\
\text { rata }\end{array}$ & $\mathbf{R 1}$ & $\mathbf{R 2}$ & $\mathbf{R 3}$ & $\begin{array}{c}\text { Rata- } \\
\text { rata }\end{array}$ & R1 & R2 & R3 & $\begin{array}{c}\text { Rata- } \\
\text { rata }\end{array}$ \\
\hline Kaca & 4,9 & 5,4 & 5,1 & 5,1 & 4,7 & 4,6 & 4,8 & 4,7 & 4,9 & 4,4 & 4,7 & 4,7 \\
\hline 50 & 5,4 & 5,9 & 5,4 & 5,6 & 5,2 & 5,1 & 5,1 & 5,1 & 5,5 & 4,5 & 5,1 & 5,0 \\
\hline 100 & 5,5 & 6,4 & 5,7 & 5,9 & 5,6 & 5,4 & 5,6 & 5,5 & 6,0 & 4,6 & 5,4 & 5,3 \\
\hline 150 & 6,0 & 6,5 & 6,1 & 6,2 & 6,0 & 5,7 & 5,8 & 5,8 & 6,4 & 4,9 & 5,7 & 5,7 \\
\hline
\end{tabular}

Hasil uji daya sebar terhadap formula I, II, III, dan IV menunjukkan bahwa keempat formula dapat menyebar dengan baik. Hal ini memungkinkan zat aktif teh hijau dapat menyebar pada permukaan kulit dengan baik dan efek farmakologinya merata. Diameter penyebaran paling besar ditunjukkan oleh formula III, sehingga dapat dikatakan kemampuan penyebaran gel dengan basis PEG 400:4000 (15:65) adalah yang paling tinggi, namun dari segi konsistensi sediaannya yang cair, gel dengan basis PEG ini tidak menunjukkan konsistensi gel yang baik. Kemampuan menyebar dari ketiga gel yang lain, jika dibandingkan maka kemampuan menyebar gel formula IV lebih tinggi daripada formula II, dan kemampuan menyebar gel formula II lebih tinggi daripada formula I.

\section{4) Uji daya lekat}

Uji daya lekat dilakukan dengan tujuan untuk melihat kemampuan gel melekat pada kulit. Syarat sediaan topikal yang baik adalah mempunyai daya lekat yang tinggi, sehingga zat aktif dari sediaan mempunyai waktu kontak yang lama dengan kulit dan memberikan waktu yang cukup untuk berefek. Hasil uji daya lekat ditunjukkan pada tabel XI. 
Tabel XI. Hasil uji daya lekat

\begin{tabular}{|c|c|c|c|c|c|c|c|c|c|c|c|c|}
\hline \multirow{3}{*}{$\begin{array}{c}\text { Repli- } \\
\text { kasi }\end{array}$} & \multicolumn{12}{|c|}{ Waktu pelekatan (detik) } \\
\hline & \multicolumn{3}{|c|}{ Formula I } & \multicolumn{3}{|c|}{ Formula II } & \multicolumn{3}{|c|}{ Formula III } & \multicolumn{3}{|c|}{ Formula IV } \\
\hline & I1 & I2 & I3 & II1 & II2 & II3 & III1 & III2 & III3 & IV1 & IV2 & IV3 \\
\hline 1 & 0,78 & 0,40 & 0,47 & 0,37 & 0,51 & 0,48 & 0,43 & 0,40 & 0,42 & 0,51 & 0,35 & 0,48 \\
\hline 2 & 0,50 & 0,50 & 0,46 & 0,40 & 0,56 & 0,40 & 0,41 & 0,42 & 0,41 & 0,42 & 0,40 & 0,48 \\
\hline 3 & 0,37 & 0,37 & 0,39 & 0,44 & 0,50 & 0,57 & 0,44 & 0,41 & 0,43 & 0,41 & 0,41 & 0,37 \\
\hline $\begin{array}{c}\text { Rata- } \\
\text { rata }\end{array}$ & 0,55 & 0,42 & 0,44 & 0,40 & 0,52 & 0,48 & 0,43 & 0,41 & 0,42 & 0,47 & 0,39 & 0,44 \\
\hline
\end{tabular}

Hasil uji daya lekat menunjukkan bahwa keempat formula mempunyai daya lekat yang kurang baik dengan waktu pelekatan pada alat percobaan $<1$ menit, namun hal ini dapat dimaklumi untuk sediaan gel, mengingat konsistensinya yang bebas lemak.

\section{5) Uji daya proteksi}

Uji daya proteksi bertujuan untuk melihat kemampuan basis dalam melindungi zat aktif sekaligus melindungi kulit terhadap bahan-bahan yang bersifat asam atau basa yang dapat mengiritasi kulit. Uji daya proteksi dilakukan dengan kertas saring $(10$ x $10 \mathrm{~cm})$ yang dibasahi larutan phenolphthalein (pp) sebagai indikator, kemudian dikeringkan. Kertas yang telah kering tersebut diolesi dengan
0,5 g gel pada satu sisi permukaan seperti lazimnya orang menggunakan gel (1). Pada kertas saring lain dibuat area 2,5 x 2,5 cm dengan pembatas parafin padat yang dilelehkan (2). Potongan kertas saring (2) kemudian ditempelkan di atas (1) dan ditetesi dengan $\mathrm{NaOH} 0,02 \mathrm{~N}$. Timbulnya noda kemerahan pada bagian kertas yang dibasahi dengan larutan PP diamati dan dicatat waktu yang diperlukan mulai saat penetesan $\mathrm{NaOH}$ hingga munculnya warna merah. Timbulnya warna merah tersebut adalah karena adanya reaksi antara $\mathrm{NaOH}$ dengan indikator $\mathrm{PP}$, sehingga jika timbulnya warna merah relatif cepat maka dapat dikatakan daya proteksi sediaan kurang. Hasil uji daya proteksi keempat formula gel dapat dilihat pada tabel XII.

Tabel XII. Hasil uji daya proteksi

\begin{tabular}{ccccccccccccc}
\hline Replikasi & \multicolumn{9}{c}{ Waktu timbulnya bercak merah setelah ditetesi NaOH 0,02N (detik) } \\
\cline { 2 - 12 } & \multicolumn{3}{c}{ Formula I } & \multicolumn{3}{c}{ Formula II } & \multicolumn{3}{c}{ Formula III } & \multicolumn{3}{c}{ Formula IV } \\
\cline { 2 - 13 } & I1 & I2 & I3 & II1 & II2 & II3 & III1 & III2 & III3 & IV1 & IV2 & IV3 \\
\hline 1 & 0,60 & 0,47 & 0,41 & 0,47 & 0,32 & 0,31 & 1,25 & 1,05 & 1,30 & 0,38 & 0,50 & 0,34 \\
\hline 2 & 0,65 & 0,44 & 0,43 & 0,35 & 0,35 & 0,38 & 1,20 & 1,10 & 1,25 & 0,42 & 0.60 & 0,65 \\
\hline 3 & 0,50 & 0,39 & 0,42 & 0,44 & 0,41 & 0,41 & 1,19 & 1,18 & 1,27 & 0,50 & 0,44 & 0,43 \\
\hline Rata-rata & $\mathbf{0 , 5 8}$ & $\mathbf{0 , 4 3}$ & $\mathbf{0 , 4 2}$ & $\mathbf{0 , 4 2}$ & $\mathbf{0 , 3 6}$ & $\mathbf{0 , 3 7}$ & $\mathbf{1 , 2 0}$ & $\mathbf{1 , 1 1}$ & $\mathbf{1 , 3 0}$ & $\mathbf{0 , 4 3}$ & $\mathbf{0 , 5 1}$ & $\mathbf{0 , 4 7}$ \\
\hline
\end{tabular}

Hasil uji daya proteksi menunjukkan bahwa keempat formula gel memiliki daya proteksi yang kurang baik, dilihat dari waktu timbulnya warna merah yang relatif cepat, yakni kurang lebih 1 menit. Daya proteksi yang baik merupakan syarat bagi sediaan topikal, namun untuk sediaan gel daya proteksi yang kurang baik dapat dimaklumi karena sediaan gel mengandung banyak air.

\section{Uji Aseptabilitas}

Uji aseptabilitas bertujuan untuk melihat tingkat kenyamanan gel saat digunakan. Uji aseptabilitas pemakaian sediaan dilakukan terhadap 20 responden laki-laki berusia diatas 20 tahun. Parameter uji yang diamati antara lain: pengolesan, kelembutan, efek dingin, pengeringan, dan daya lengket. Ketentuan penelitian untuk tiap parameter uji dilambangkan dengan tanda + (diberi skor $=1),++\quad$ (diberi skor=2), dan +++ (diberi skor=3) dengan makna sebagaimana dipaparkan dalam tabel III. Skor tiap parameter kemudian dijumlah dan dihitung rata-ratannya. Hasil uji aseptabilitas ditunjukkan pada lampiran tabel XIII. 
Tabel XIII. Hasil uji aseptabilitas

\begin{tabular}{|c|c|c|c|c|c|}
\hline \multirow[t]{2}{*}{ Formula } & \multicolumn{5}{|c|}{ Skor pada tiap parameter } \\
\hline & Pengolesan & Kelembutan & Efek dingin & Pengeringan gel & Daya lengket \\
\hline $\mathrm{I} 1$ & 2,45 & 2,50 & 2,00 & 2,00 & 2,00 \\
\hline $\mathrm{I} 2$ & 2,50 & 2,55 & 2,65 & 2,00 & 1,70 \\
\hline $\mathrm{I} 3$ & 2,40 & 2,40 & 2,45 & 2,15 & 2,45 \\
\hline II1 & 2,00 & 2,00 & 2,00 & 2,50 & 2,15 \\
\hline II2 & 2,00 & 2,00 & 2,00 & 2,50 & 2,15 \\
\hline II3 & 2,00 & 2,00 & 2,00 & 2,00 & 2,00 \\
\hline III1 & 2,60 & 2,65 & 2,25 & 2,30 & 2,00 \\
\hline III2 & 2,70 & 2,00 & 2,05 & 1,60 & 2,45 \\
\hline III3 & 3,00 & 2,00 & 2,00 & 1,45 & 2,50 \\
\hline IV1 & 2,00 & 2,00 & 1,50 & 1,15 & 2,45 \\
\hline IV2 & 2,00 & 2,00 & 2,00 & 1,15 & 2,50 \\
\hline IV3 & 2,00 & 2,00 & 1,15 & 1,60 & 2,65 \\
\hline
\end{tabular}

Keterangan: data yang dicetak tebal menunjukkan skor tertinggi dari tiap parameter.

Hasil uji aseptabilitas menunjukkan bahwa gel formula I memiliki skor tertinggi pada parameter pengolesan, kelembutan, dan efek dingin. Hal ini menunjukkan bahwa formula I paling nyaman dioleskan, paling lembut dan efek dingin paling terasa. Sifat pengeringan gel yang paling baik dimiliki oleh gel formula II, formula I juga memiliki sifat pengeringan gel yang baik walaupun skornya berada di bawah formula II. Daya lengket yang paling baik ditunjukkan pada formula IV. Dari uji aseptabilitas yang dilakukan, diketahui bahwa formula I memiliki parameter kenyamanan penggunaan yang paling tinggi.

\section{Uji Iritasi Primer}

Uji iritasi primer yang dilakukan meggunakan metode Draize yang telah dimodifikasi. Sejumlah 0,5 gram gel dioleskan pada hewan uji, kemudian ditutup dengan perban. Tempelan dibiarkan di kulit selama 4 jam, kemudian diambil dan diamati terjadinya eritema dan edema pada interval waktu 1 jam; 24 jam; 48 jam; 72 jam; 1 minggu. Terjadinya eritema dan edema diberi skor sesuai dengan tabel evaluasi reaksi iritasi kulit (tabel IV). Hasil uji iritasi primer dapat dilihat pada tabel XISSV.

Hasil uji iritasi primer menunjukkan bahwa keempat formula gel mempunyai indeks iritasi $<2$. Hal ini menunjukkan bahwa keempat formula gel kurang merangsang iritasi kulit, sehingga aman untuk digunakan.

\section{E. Uji Aktivitas Penyubur Rambut}

Uji aktivitas penyubur rambut dilakukan dengan mencukur rambut hewan uji dengan ukuran $2 \times 2 \mathrm{~cm}^{2}$. Bagian yang dicukur diolesi dengan gel yang telah dibuat. Pengolesan dilakukan sekali sehari selama 1 bulan. Pengamatan pertumbuhan rambut hewan uji dilakukan pada akhir percobaan. Replikasi untuk masing formula gel sebanyak tiga kali. Hasil uji aktivitas penyubur rambut dapat dilihat pada tabel XV. 
Tabel XIV. Hasil uji iritasi primer gel

\begin{tabular}{|c|c|c|c|c|c|c|c|c|c|c|c|}
\hline \multirow{4}{*}{$\begin{array}{l}\text { Pengolesan } \\
\text { gel }\end{array}$} & \multirow{4}{*}{$\begin{array}{l}\text { Mencit } \\
\text { Kontrol }\end{array}$} & \multicolumn{10}{|c|}{ Skor } \\
\hline & & \multicolumn{5}{|c|}{ Eritema pada jam ke- } & \multicolumn{5}{|c|}{ Edema pada jam ke- } \\
\hline & & 1 & 24 & 48 & 72 & 168 & 1 & 24 & 48 & 78 & 168 \\
\hline & & 0 & 0 & 0 & 0 & 0 & 0 & 0 & 0 & 0 & 0 \\
\hline \multirow[t]{3}{*}{ I1 } & 1 & 0 & 1 & 1 & 1 & 1 & 0 & 0 & 0 & 0 & 0 \\
\hline & 2 & 1 & 1 & 1 & 1 & 1 & 0 & 0 & 0 & 0 & 0 \\
\hline & 3 & 0 & 0 & 0 & 0 & 0 & 0 & 0 & 0 & 0 & 0 \\
\hline \multirow[t]{3}{*}{$\mathrm{I} 2$} & 1 & 0 & 0 & 0 & 0 & 0 & 0 & 0 & 0 & 0 & 0 \\
\hline & 2 & 0 & 0 & 0 & 0 & 0 & 0 & 0 & 0 & 0 & 0 \\
\hline & 3 & 0 & 0 & 0 & 0 & 0 & 0 & 0 & 0 & 0 & 0 \\
\hline \multirow[t]{3}{*}{ I3 } & 1 & 1 & 1 & 1 & 1 & 1 & 0 & 0 & 0 & 0 & 0 \\
\hline & 2 & 0 & 0 & 0 & 1 & 1 & 0 & 0 & 0 & 0 & 0 \\
\hline & 3 & 1 & 1 & 1 & 1 & 1 & 0 & 0 & 0 & 0 & 0 \\
\hline \multirow[t]{3}{*}{ III } & 1 & 0 & 0 & 0 & 0 & 0 & 0 & 0 & 0 & 0 & 0 \\
\hline & 2 & 0 & 0 & 0 & 1 & 1 & 0 & 0 & 0 & 0 & 0 \\
\hline & 3 & 0 & 1 & 1 & 1 & 1 & 0 & 0 & 0 & 0 & 0 \\
\hline \multirow[t]{3}{*}{ II2 } & 1 & 0 & 0 & 0 & 0 & 0 & 0 & 0 & 0 & 0 & 0 \\
\hline & 2 & 0 & 0 & 0 & 0 & 0 & 0 & 0 & 0 & 0 & 0 \\
\hline & 3 & 1 & 1 & 1 & 1 & 1 & 0 & 0 & 0 & 0 & 0 \\
\hline \multirow[t]{3}{*}{ II3 } & 1 & 0 & 0 & 0 & 0 & 0 & 0 & 0 & 0 & 0 & 0 \\
\hline & 2 & 0 & 0 & 0 & 0 & 0 & 0 & 0 & 0 & 0 & 0 \\
\hline & 3 & 1 & 1 & 1 & 1 & 1 & 0 & 0 & 0 & 0 & 0 \\
\hline \multirow[t]{3}{*}{ III1 } & 1 & 0 & 0 & 0 & 1 & 1 & 0 & 0 & 0 & 0 & 0 \\
\hline & 2 & 1 & 1 & 1 & 1 & 1 & 0 & 0 & 0 & 0 & 0 \\
\hline & 3 & 0 & 1 & 1 & 1 & 1 & 0 & 0 & 0 & 0 & 0 \\
\hline \multirow[t]{3}{*}{ III2 } & 1 & 0 & 0 & 0 & 0 & 0 & 0 & 0 & 0 & 0 & 0 \\
\hline & 2 & 0 & 0 & 1 & 1 & 1 & 0 & 0 & 0 & 0 & 0 \\
\hline & 3 & 0 & 0 & 0 & 0 & 1 & 0 & 0 & 0 & 0 & 0 \\
\hline \multirow[t]{3}{*}{ III3 } & 1 & 1 & 1 & 1 & 1 & 1 & 0 & 0 & 0 & 0 & 0 \\
\hline & 2 & 0 & 0 & 0 & 0 & 0 & 0 & 0 & 0 & 0 & 0 \\
\hline & 3 & 0 & 0 & 0 & 0 & 0 & 0 & 0 & 0 & 0 & 0 \\
\hline \multirow[t]{3}{*}{ IV1 } & 1 & 0 & 1 & 1 & 1 & 1 & 0 & 0 & 0 & 0 & 0 \\
\hline & 2 & 0 & 0 & 0 & 0 & 0 & 0 & 0 & 0 & 0 & 0 \\
\hline & 3 & 0 & 0 & 0 & 0 & 0 & 0 & 0 & 0 & 0 & 0 \\
\hline \multirow[t]{3}{*}{ IV2 } & 1 & 1 & 1 & 1 & 1 & 1 & 0 & 0 & 0 & 0 & 0 \\
\hline & 2 & 0 & 1 & 1 & 1 & 1 & 0 & 0 & 0 & 0 & 0 \\
\hline & 3 & 0 & 0 & 0 & 0 & 0 & 0 & 0 & 0 & 0 & 0 \\
\hline \multirow[t]{3}{*}{ IV3 } & 1 & 0 & 0 & 0 & 0 & 0 & 0 & 0 & 0 & 0 & 0 \\
\hline & 2 & 0 & 1 & 1 & 1 & 1 & 0 & 0 & 0 & 0 & 0 \\
\hline & 3 & 0 & 1 & 1 & 1 & 1 & 0 & 0 & 0 & 0 & 0 \\
\hline
\end{tabular}

Tabel XV . Hasil uji aktivitas penyubur rambut pada mencit jantan BALB/c

\begin{tabular}{|c|c|c|c|c|c|c|c|c|c|c|c|c|c|}
\hline \multirow[t]{3}{*}{ Replikasi } & \multicolumn{13}{|c|}{ Panjang pertumbuhan rambut mencit $(\mathrm{cm})$ pada perlakuan dengan gel } \\
\hline & \multirow[t]{2}{*}{ Kontrol } & \multicolumn{3}{|c|}{ Formula I } & \multicolumn{3}{|c|}{ Formula II } & \multicolumn{3}{|c|}{ Formula III } & \multicolumn{3}{|c|}{ Formula IV } \\
\hline & & I1 & I2 & I3 & II1 & II2 & II3 & III1 & III2 & III3 & IV1 & IV2 & IV3 \\
\hline 1 & 0,7 & 1,3 & 1,2 & 1,3 & 1,0 & 1,0 & 0,9 & 0,7 & 0,8 & 0,7 & 1,1 & 1,0 & 1,1 \\
\hline 2 & 0,8 & 1,4 & 1,3 & 1,2 & 0,8 & 0,9 & 0,9 & 0,8 & 0,8 & 0,7 & 1,0 & 1,0 & 1,0 \\
\hline 3 & 0,8 & 1,3 & 1,2 & 1,2 & 0,9 & 0,8 & 0,8 & 0,7 & 0,7 & 0,8 & 0,9 & 1,0 & 1,1 \\
\hline Rata-rata & 0,8 & 1,3 & 1,2 & 1,2 & 0,9 & 0,9 & 0,9 & 0,7 & 0,8 & 0,7 & 1,0 & 1,0 & 1,1 \\
\hline
\end{tabular}

Hasil uji aktivitas penyubur rambut gel ekstrak teh hijau menunjukkan bahwa rata-rata panjang pertumbuhan rambut mencit kontrol (tanpa perlakuan) adalah $0,8 \mathrm{~cm}$. Pertumbuhan rambut mencit yang diolesi gel ekstrak teh hijau lebih panjang dibandingkan dengan kontrol, kecuali pada perlakuan dengan gel formula III, pertumbuhan rambutnya relatif sama dengan control dengan rata-rata panjang pertumbuhan $0,7 \mathrm{~cm}$. Pertumbuhan rambut mencit yang diolesi gel formula I adalah yang paling panjang yaitu $1,2 \mathrm{~cm}$, dibandingkan mencit yang diolesi ketiga formula yang lain. Hal ini menunjukkan bahwa gel formula I mampu melepaskan zat aktif ekstrak the hijau dengan baik sehingga 
menghasilkan aktivitas pertumbuhan rambut yang paling baik dibandingkan ketiga formula yang lain.

\section{Kesimpulan dan Saran}

\section{A. Kesimpulan}

1. Formula III dengan basis kombinasi PEG 400:4000 (8:72) tidak menghasilkan konsistensi sediaan gel ekstrak teh hijau yang baik karena berbentuk cair.

2. Formula gel ekstrak teh hijau yang paling optimal adalah formula I (dengan basis Carbopol 1\%, TEA 0,3\%, dan gliserin $1 \%)$, karena:

a aktivitas pertumbuhan rambut pada mencit paling tinggi (rata-rata 1,2 $\mathrm{cm}$ ) sedangkan pertumbuhan rambut pada mencit tanpa perlakuan rata-rata $0,8 \mathrm{~cm}$

b. indeks iritasi $<2$ sehinnga tidak menimbulkan iritasi pada kulit

c. tingkat kenyamanan saat digunakan paling tinggi dari segi pengolesan, kelembutan, dan pengeringan gel.

\section{B. Saran}

1. Perlu dilakukan penelitian tentang daya anti bakteri ekstrak teh hijau (Camellia sinensis L)

2. Perlu dilakukan penelitian tentang pengembangan formulasi sediaan lain dengan bahan aktif ekstrak teh hijau (Camellia sinensis $\mathrm{L}$ ).

\section{Daftar Pustaka}

Anonim, 1995, Farmakope Indonesia, Edisi IV, Departemen Kesehatan RI, Jakarta.

Anonim, 2008, Catecbin, http://en.wikipedia.org/wiki/catechin, diakses tanggal 8 November 2008.

Anonim, 2008, Green Tea Herbs With Hair Loss?, http://www.keratin.com/ac/baldnesstr eatments/greenteabaldnessuse.shtml, diakses tanggal 29 Oktober 2008.
Anonim, 2008, Green Tea Shampoo, http://www.greenteashampoo.org, diakses tanggal 29 Oktober 2008.

Ansel, H.C., 1989, Introduction to Pharmaceutical Dosage Farms, diterjemahkan oleh Ibrahim dan Farida, Edisi IV, 390-391, UI, Jakarta. Asyarie, S, dkk, 2008, Formulasi Gel elestrak The Hijau dan Seledri serta Uji Khasiatnya terbadap Pertumbuban Rambut, Abstract, Fakultas Farmasi ITB, Bandung.

Harborne, J.B., 1987, Metode Fitokimia, Edisi II, Institut Teknologi Bandung (ITB), Bandung.

Hasmani, H. A., 2006, Carbopol and its Pharmaceutical Significance: A review, http://www.pharmainfo.net/reviews/ carbopol-and-itspharmaceuticalsignificance-review, diakses pada 6 November 2008.

Lachman, L., Liebermann H. A., and Kanig, J. L., 1994, The Theory and Pratice of Industrial Pharmacy, diterjemahkan oleh Siti Suyatmi, Edisi III, 119-1120, UI Press, Jakarta.

Mursito, B., 2005, Ramuan Tradisional untuk Pelangsing Tubuh,80-82, Penebar Swadaya, Jakarta.

OS, Kwon, dkk, 2008, Human Hair Growth Enhancement In Vitro By Green Tea Epigallocatechin-3-gallate(EGCG), http://findarticles.com/p/articles/mi h b3363/is 7-8 14/ai n29373027/pg 3, diakses tanggal 29 Oktober 2008.

Voigt, R., 1995, Lebrbuch Der Pharmazeutischen Technologie, Diterjemahkan oleh Soewandhi dan Soendani Noerono, Edisi VI, 314-340, 352-355, UGM Press, Yogyakarta.

Warsitaadmadja, SM., 1997, Penuntun Ilmu Kosmetik Medik, Universitas Indonesia (UI) Press, Jakarta.

Wirakusumah, E. S., dan Setyowati, R. N., 2004, Cantik dan Bugar dengan Ramuan Nabati, 11-15, Penebar Jaya, Jakarta 